\title{
Papers
}

\section{Understanding resolution of deliberate self harm: qualitative interview study of patients' experiences}

\author{
Julia Sinclair, Judith Green
}

\begin{abstract}
Objective To explore the accounts of those with a history of deliberate self harm but who no longer do so, to understand how they perceive this resolution and to identify potential implications for provision of health services.

Design Qualitative in-depth interview study.

Setting Interviews in a community setting.

Participants 20 participants selected from a representative cohort identified in 1997 after an episode of deliberate self poisoning that resulted in hospital treatment. Participants were included if they had no further episodes for at least two years before interview.

Results We identified three recurrent themes: the resolution of adolescent distress; the recognition of the role of alcohol as a precipitating and maintaining factor in self harm; and the understanding of deliberate self harm as a symptom of untreated or unrecognised illness.

Conclusion Patients with a history of deliberate self harm who no longer harm themselves talk about their experiences in terms of lack of control over their lives, either through alcohol dependence, untreated depression, or, in adolescents, uncertainty within their family relationships. Hospital management of deliberate self harm has a role in the identification and treatment of depression and alcohol misuse, although in adolescents such interventions may be less appropriate.
\end{abstract}

\section{Introduction}

Deliberate self harm is a major public health problem. Services for patients vary widely across the country, and there is little convincing evidence for the efficacy of most treatments. ${ }^{1}$ In July 2004 the National Institute for Clinical Excellence (NICE) published guidelines on the short term management of patients who self harm, ${ }^{2}$ noting the limited evidence on effective interventions and recommending research with appropriate qualitative methods to explore patients' experiences of services and understanding of deliberate self harm. The few qualitative studies that have been conducted have used different methods but have concurred that deliberate self harm is an externalised way of representing diffuse intrinsic distress. ${ }^{3-6}$ These studies were all conducted in the period immediately after an episode of deliberate self harm; to date, qualitative research has not examined long term outcomes.

The lack of qualitative research on longer term perspectives, particularly for those who no longer harm themselves, is especially salient because of the limited efficacy of secondary prevention interventions. ${ }^{7}$ Not only are patients' accounts of deliberate self harm and the treatment received important in terms of evaluating patients' perspectives on care, they may also help to inform the development and implementation of more effective management strategies. We examined how those who had previously presented to hospital after an episode of deliberate self poisoning (19 after an overdose, one with carbon monoxide poisoning), but who had not harmed themselves in the past two years, discussed their self harming behaviour and the health services they received at the time. We explored these accounts to identify how patients accounted for this resolution.

In studying "accounts" of past experiences, we were not necessarily interested in identifying empirically valid reconstructions (that is, checking the details with the medical notes) of precipitating factors, encounters with health services, or factors leading to resolution. Instead, we explored how participants perceived the move away from deliberate self harm and what insights this could provide about the appropriateness of treatment options. We therefore analysed patients' stories in terms of what we could learn about the experiences of those who have self harmed from the stories they tell. One perspective that aided this approach was Arthur Frank's discussion of stories about illness as a way of "giving voice to the body." ${ }^{8}$ Frank defines three types of illness narrative: those of restitution, which tell of the body restored to health; those of quest, which construct illness as a journey; and those of chaos, which escape "narrative closure"-that is, remain unresolved. Subjective tales are also important in that they allow a re-evaluation of the past, enabling the story teller to make sense of the present and future. ${ }^{9}$

\section{Methods}

This qualitative in-depth interview study was part of a larger follow-up study of 150 patients. The original cohort was a representative sample of patients presenting to one UK hospital who had harmed themselves ${ }^{10}{ }^{11}$ and were recruited as part of a multicentre study on parasuicide in $1997 .{ }^{12}$ Of this original cohort, 90 agreed to follow-up and were still alive and contactable after seven years. Of these, 31 had not harmed themselves in the past two years, still lived in England, and were willing to participate in an in-depth interview. We purposively selected 20 participants to reflect the sex and history of deliberate self harm of patients in the original cohort (table 1$).^{13}$

A psychiatrist who was involved in the larger cohort study but had no clinical responsibility interviewed participants. To offset the potential framing of interviewees' accounts through a professional framework (that is, telling a doctor what they think a doctor will want to hear), participants chose the interview settings, usually their own home. We also used a relatively open interview schedule (box 1), inviting patients to talk about their lives now 


\begin{tabular}{|c|c|c|}
\hline Characteristic & $\begin{array}{l}\text { No }(\%) \text { in qualitative } \\
\text { sample }(\mathrm{n}=20)\end{array}$ & $\begin{array}{c}\text { No }(\%) \text { in original cohort } \\
(n=150)\end{array}$ \\
\hline Men & $8(40)$ & $58 \quad(39)$ \\
\hline Women & $12(60)$ & $92(61)$ \\
\hline Single episode of DSH & $6(30)$ & $47(31)$ \\
\hline$>1$ episode of DSH & $14(70)$ & $103(69)$ \\
\hline
\end{tabular}

$\mathrm{DSH}=$ deliberate self harm.

and in 1997 and to highlight important events in the intervening period. All topics were covered in each interview, which lasted between 45 minutes and an hour. Interviews were taped with permission, and corrected transcripts were imported into QSR NVivo software (QSR International, Melbourne, Vic). Analysis was both thematic and narrative. Thematic analysis used some of the principles of grounded theory, ${ }^{14}{ }^{15}$ such as open coding of early data and working with peer review groups of qualitative researchers, who discussed both the emerging coding scheme and coding decisions to ensure potential avenues of analysis were explored. All data were entered and coded, aiding a thorough and comprehensive analysis, and recurrent themes then identified across the dataset. ${ }^{16}$ Narrative analysis entailed an in-depth reading of transcripts to characterise the structures of the stories by Frank's model of illness narratives. ${ }^{8}$

\section{Results}

JS interviewed 12 women and eight men, 14 of whom had harmed themselves on more than one occasion. To preserve the anonymity of the participants we have not detailed individual characteristics but have summarised them as a group in table 2 . We have focused on three key narratives of resolution that emerged from the analysis and typified most (18/20) of the participants. The two other participants described a single episode of deliberate self harm in the context of overwhelming acute life difficulties.

\section{Box 1 Interview topic guide}

- Can you tell me a little bit about how things are for you at the moment? (take me through a typical day or typical week?)

- Going back to 1997, tell me how things were at that time? (can you remember what led up to your being in hospital?)

- In what way do you think things have changed (or stayed the same) since that time? (take me through what has happened in the past seven years?)

- What kind of situation in the future do you think might result in your harming yourself again? (if you can't envisage one, why not?) (Otherwise explore avenues of support/danger)

\section{Resolution of adolescent chaos}

There were nine participants in this group, all of whom were still dependent in some way on their parents in 1997. For them, the defining difference between "now" and the time of their deliberate self harm was the resolution of their lack of control within the family structure. Most talked of the unpredictability of family life in 1997, ranging from specific accounts of sexual abuse or physical violence to more general memories of confusion or feeling unsupported (box 2). Family life was recounted as not just chaotic but also failing to provide any validation of their experiences at the time; interviewees recalled feeling that they were "not heard" (six participants) or that their story was considered unimportant: "I told my mum that my dad had abused me and she didn't believe me. And she apparently told my brother what I had said and my brother didn't believe me either and they just both wanted to carry on" (participant 1, female, age 19 in 1997).

Within this context, it is understandable how feelings of hopelessness associated with suicidal acts can build and gain momentum, and participants told of overwhelming feelings of isolation and despair. Although recalling events of up to seven years ago, several became tearful when talking of their feelings at that time. In Frank's types of illness stories, the parts of the interview where these participants recalled their adolescence were typically "chaos" narratives, full of pauses and dislocations: "I don't think there were any specific events, it just all got too much [pause]. I just sat there and thought 'I don't want to do this anymore,' it was like, 'life's been pretty shit so far and I think it's going to be pretty shit,' or I perceived that it wasn't going to get any better and I was just tired. And didn't want to fight anymore. I knew I'd have another year at home [pause] ... and I'd just had enough ..." [Long pause, very tearful] (participant 1).

While three people in this group described a wish to die at that time, others acknowledged that the key motivation was for someone to hear and validate their distress. No participants from this group said that help offered as part of the hospital assessment was beneficial. Instead, admission to hospital was remembered as a frightening experience which furthered their perception of lack of control: "I remember thinking 'I'm not like them, you're not putting me in there [deliberate self harm ward].' And then them putting me in this bay in this awful, awful ward where there were just a real variety, I guess it was a bit like a pick and mix bag and it was just, it was awful, it was absolutely awful and I think I was probably quite young by comparison with the majority of the people there and it was yeah it was a horrible, horrible experience" (participant 3).

It is perhaps not surprising that several participants talked of difficulty in engaging with a potentially helpful but new relationship offered during assessment, either seeing it as a requirement they had to agree to, to be allowed home, or as not matching

Table 2 Characteristics of three "narrative" groups at index episode

\begin{tabular}{|c|c|c|c|c|}
\hline Characteristic & Adolescent & Illness & Alcohol & Other \\
\hline No in group & 9 & 5 & 4 & 2 \\
\hline Only episode of DSH & 2 & 2 & 0 & 2 \\
\hline $\begin{array}{l}\text { Mean (range) years since last } \\
\text { episode }\end{array}$ & $3.9(3.3-7.0)$ & $6.3(5.3-7.5)$ & $5.2(3.5-6.6)$ & $6.7(6.5-6.9)$ \\
\hline Diagnosis at index episode & $\begin{array}{l}\text { Harmful use of alcohol (1), none (2), } \\
\text { depression (6) }\end{array}$ & Depression (4), OCD (1) & $\begin{array}{l}\text { Harmful use of alcohol (1), alcohol } \\
\text { dependence (3) }\end{array}$ & $\begin{array}{l}\text { None (1), somatoform pain disorder } \\
\text { (1) }\end{array}$ \\
\hline Mean (range) index SIS & $10(5-20)$ & $13(3-24)$ & $8(3-12)$ & $18(13-23)$ \\
\hline Employment status at index episode & $\begin{array}{l}\text { Full time education (4), unemployed } \\
\text { (1), sick (1), employed (3) }\end{array}$ & Employed (4), disabled (1) & Unemployed (3), housewife (1) & Employed (1), disabled (1) \\
\hline $\begin{array}{l}\text { Mean (range) age at index episode } \\
\text { (years) }\end{array}$ & $19.2(16-25)$ & $39.6(33-48)$ & $38.8(24-48)$ & 41 (34-48) \\
\hline
\end{tabular}


their needs at that time: "So I went to see this counsellor and she just took me through this cognitive whatever [therapy], she spent an hour going through all this rubbish, and I just wanted to talk and she just wanted to go through her theories" (participant 6).

Three participants mentioned helpful existing relationships with professionals such as general practitioners or school counsellors: for example, "He [general practitioner] was like rock. He really was, he was genuinely concerned for me and I could tell he was. He was really worried and in a way he made me feel better you know that someone cared and he, you know, he would see me every, maybe every month every two months just to see how everything was and till he retired really so he was a great help" (participant 8).

The narrative style shifts when these participants describe their lives now, in which a sense of autonomy is the key change

\section{Box 2 Unpredictability of family life}

\section{Context}

Unpredictability and powerlessness within family situation, a lack of validation of unique personal experiences; a sense of not being heard or of being unimportant:

I mean we had the slipper and we had the belt and when we did get a smack it was a smack, and occasionally you know I'd be on the brunt of someone losing their rag and I'd get a, I wouldn't call it a beating ... just a good hiding, which I still, I think was too much ... My mum's overdoses get talked about, about the fact that she slit her wrists and she was in [hospital], mine don't get spoken about at all ... (participant 2, female, aged 20 in 1997)

My stepmother ... was a nutcase [had manic depression], when she was not high or low she was actually a very nice woman... but then she had an episode ... I actually felt quite scared of her; she went really high and was just very scary ... I did feel very rejected which was really hard, and my father is very old school and just couldn't be doing with this teenager who was crying over this pathetic guy who was a complete loser anyway, and my mother didn't want to know, you know "you went to live with your father let him deal with it" (participant 3, female, aged 16 in 1997)

[Things at home had] never been stable, I mean it was just now my brothers and sisters had gone it was worse ... Dad's ... he is a manic depressive ... but constructs, whether he knows he's constructing them or not, fanciful stories and lies of how things are getting at him and doing things to him (participant 4, male) [Dad] had been drinking ... I don't think he meant to hurt me, he just walked past and kicked me right in the hip but Tom [little brother] went and reported it so we got put on the child protection list. I think it's the child protection list. We were on there until I was 16 (participant 5, female)

My mother used to go through my letters ... she read the letters and interpreted them the wrong way ... she made me sit in front of her and rip them, these letters, I had to rip them. She ruled that house, and the only way sometimes to get yourself heard was to do that [self harm]. I remember like with the clarinet, she insisted for years that I played the clarinet and she said "I pay $£ 10$ a week for you to have these lessons," and I hated the things, so I got my fingers and I remember rubbing them raw to make them bleed so I couldn't press the keys because she just wouldn't listen (participant 6, male, aged 21 in 1997)

They had a lot of plans laid out for me and I had to get certain grades so when I didn't they weren't very happy at all ... My mother, she's an alcoholic and at that age I didn't understand a lot of what she said and what she did, it wasn't actually her fault but I just took it personally (participant 7, female)

I would go home crying and say that they'd broke my pens that I'd got for my birthday, and it would be "well what did you do to provoke them?" (participant 8, male, aged 20 in 1997) identified. In Frank's classification, the stories about "life now" are essentially "quest narratives," in which they describe successfully breaking away from their family and achieving independence as adults. While this involves (often onerous) responsibilities, it also provides separation from reliance on what were typically unpredictable family environments. Participants describe their lives now as having a sense of purpose, allowing them enough control to manage their responses to distress in a less self destructive way: "I'm responsible for [the baby] you know. I've stopped being so selfish about myself, worrying about my hang-ups and stuff. I've got someone else to think about, I've got a reason for getting up out of bed in the morning, I've got a reason for living now I've got a purpose to my life, I want to give my boy the best life that I can" (participant 2).

\section{Recognition of alcohol as a factor}

The second recurring story, which dominated for four participants, was that of recognising alcohol as a factor in deliberate self harm. All four, who were abstinent when interviewed, had a history of considerable alcohol misuse in 1997 (box 3). Looking back, they attributed their use of alcohol to an attempt to escape from difficult emotions but now saw it as precipitating a vicious cycle of low self esteem and self loathing: "I used to just get stressed out and think 'right hit the bottle.' Of course I'd hit the bottle, get all depressed, at first I'd feel a bit better, more relaxed ... then I'd end up being like a volcano where I'd explode and I'd either go and hit out at somebody or hit back on myself because I can't cope with this and that's when I'd hit myself hard" (participant 9, female).

All four of these participants clearly relate that admission to hospital after deliberate self harm acted as only a temporary res-

\section{Box 3 Alcohol narrative themes}

\section{Experiences of hospital care}

I think there was an alcoholic team but to be quite honest with you it was pretty nondescript, what I know about the illness now, pretty nondescript. And I suppose I wasn't educated enough to my belief that I realised that alcohol was so damaging with a low mood (participant 10, female)

Well I didn't take them intentionally to die, I took them, um, it was like more of a comfort, you take them because it takes you away and you're in a hospital and you haven't got to see anybody ... (participant 11, female)

I mean they were very kind, very good but there was absolutely nothing they could do. They had no resources and no trained staff or anything... I was begging for help. The reality was, although it's probably one of the largest diseases in this country, there isn't any help. If they [family] hadn't been able to do anything, my family hadn't helped, I'm probably convinced that the system would have just left me to die, because it did nothing, it did absolutely nothing (participant 12 , male)

\section{Decisions to change}

I do remember, this is six years ago, I remember just waking up and feeling this can't go on; I cannot go on living this life of lying in bed and drinking ... if I start drinking I might as well be dead because the life that it gave me, because when I drink I choose not to function (participant 10)

I knew how much it hurt them [family] and how much it hurt me so and as I'm a nicer person, my husband's nicer towards me, life's just generally a hell of a lot better, things are getting done in the house (participant 9)

The fact that I don't drink any more basically allows me a life. Drink effectively removed the ability to function as a normal human being (participant 12) 
pite from their difficulties; the process and practicalities of stopping drinking, which were key in affecting their self harm behaviour, were either not sought or unavailable: "No, the self harm was a cry for help, it wasn't an attempt to kill myself. It was actually the alcohol that was killing me. I just used another drug because at the end of the day if you ring up a hospital and say you're drunk they tell you to bugger off, if you ring up and say you've swallowed a bottle of pills, they let you in" (participant 12).

The effect of abstinence was framed within a restitution narrative, in that abstaining was, in these stories, the route to regained self pride and individuality and an immediate end to their acts of self harm that required hospital admission: "I feel like I've grown up a lot and I can actually think for myself because I'm not drinking, and I don't know why I didn't do it years ago, I just thought [alcohol] was a good solution ..." (participant 11).

\section{Seeing deliberate self harm as a consequence of illness}

For this group of participants, their overdose was narratively constructed as the "trigger" for getting help. In contrast with the narratives of participants in the adolescent group, hospital services were seen as a positive factor in the resolution of self harm. All described significant depressive symptoms at the time, culminating in the index attempt in 1997, including descriptions of isolation and desperation (box 4). In retrospect, they understood that deliberate self harm could be seen as a symptom of illness, but at the time they were faced with feelings of hopelessness that seemed insoluble: "I remember going to see a GP and saying and explaining how bad things had got and how desperate I had become and I really didn't think I was getting through to him at all. I didn't think they were taking me at all seriously" (participant 13 , male)

What differs in the narratives of this group is that admission to hospital was seen as part of the process of recovery, with the recognition of suicidal behaviour as being a symptom of depression, which was seen as manageable by their own efforts with support from professional services. They all saw the potential to be in the same position again, but by constructing their experiences within a "restitution" type narrative of illness, they have identified legitimate avenues of support that were not previously open to them.

\section{Discussion}

The narratives people construct to make sense of their experiences offer an alternative perspective for researchers and policy makers to consider when planning services and future intervention studies. This study was limited by its small sample size, drawn from those in a cohort of patients who no longer harm themselves, and we do not know how far our findings can be generalised to those with ongoing episodes of deliberate self harm. The perspectives explored here, however, offer some tentative suggestions for health service provision that could be developed for further research.

Rates of deliberate self harm in adolescents are continuing to rise. ${ }^{18}$ Our study suggests that secondary services have limited impact in young people, who reported difficulties engaging with unfamiliar staff (as opposed to trusted and known general practitioners and counsellors) as part of what was perceived as a traumatic hospital admission. Key to their recalled needs was someone outside the family who has space and time "just to talk" and hear a story not considered important within the family. Only a small percentage of adolescents who harm themselves present to hospital services, ${ }^{19}$ and while these results can be generalised only to them, they do suggest the imperative for finding solutions outside the emergency department, in primary care or education systems.

Secondly, it is important that several participants identified abstaining from alcohol as key to the resolution of deliberate self harm. Given the correlation between alcohol dependence and the risk of deliberate self harm and suicide, ${ }^{20}{ }^{21}$ as well as the potential for brief interventions in emergency departments, ${ }^{22}$ this may be an issue for further research, particularly as some participants saw deliberate self harm as a way of accessing services.

Finally, the recognition and treatment of depression, especially in men, in primary care remains important in the prevention of suicidal behaviour, as is the greater challenge of public education campaigns to improve public (and professional) understanding of mental illness and the effective treatments available.

\section{Conclusion}

We have determined how a group of people who have not harmed themselves for several years account for the resolution of their behaviour. The three recurrent narratives that emerged

\section{Box 4 Illness narrative themes}

\section{Feelings at time of deliberate self harm}

It wasn't a rational process with rational or even irrational thoughts going through my mind, it was just a physical reflex action, a craving for comfort I suppose, like an addiction, a physical addiction. I can't actually put specific psychological thoughts to it apart from the craving for comfort. And possibly the feeling of complete black despair (participant 12)

It had in no way occurred to me that I might be ill. I hadn't even thought about depression being involved, never crossed my mind

.. I I didn't see avenues. Going to the doctor didn't even enter my head (participant 14, male)

I felt useless I suppose, I felt I couldn't care for the children, that they were better off without me, I sincerely thought that .. although I loved the children desperately, I thought they would be better off, really genuinely, because life was so stressful for everybody, for my husband (patient 15 , female)

\section{Avenues of support}

My doctor said that I will be taking it [medication] for the rest of my life which I've sort of come to accept really, the same as if I was a diabetic or whatever that would be, I'd have to take some form of medication for that and I've just come to the conclusion that some people are born with certain chemical defects in their brain or whatever and I'm one of those people and I come from a line of those people, my parents, so it's through no particular fault of my own (participant 13)

About three years, two or three years [in group therapy] and I've suddenly been put in touch with ... the wounded side of myself with painful memories and I find that my delusions about people I have in the outside world have transferred to members of the group so everything's reproduced there so that's quite helpful really (participant 12)

I suppose I know [taking an overdose] is just going to make things worse not better and I think I don't let things get to that stage any more, if I feel that I really can't cope with things, you know I will go off, I will take the dog for a walk, or even just spend a whole day away and just switch off from it really, and I don't feel guilty [about doing that] (participant 16, female) If I felt any differently I would certainly get me to the doctors and say, "look you know I'm still taking these [antidepressants] but x, $\mathrm{y}$, or $\mathrm{z}$ is, or is not happening, should we be investigating this?" and I would be doing that with total confidence that my doctor would ... (participant 14) 


\section{What is already known on this topic}

Rates of deliberate self harm continue to rise within the UK

There is limited evidence for the efficacy of most treatments available

\section{What this study adds}

Patients with a history of deliberate self harm (who no longer harm themselves) talk about their experiences in terms of lack of control over their lives, either through alcohol dependence, untreated depression or, in adolescents, uncertainty within their family relationships

Hospital management of deliberate self harm has a role in the identification and treatment of depression and alcohol misuse, although in adolescents such interventions may be less appropriate

suggest diverse populations with diverse service needs, many of which are currently inadequately dealt with within the health service.

Contributors: JS carried out the interviews, analysed the transcripts, and discussed the emerging coding schemes and decisions with JG. JS is guarantor.

Funding: This study was funded as part of the MRC Training Fellowship held by JS.

Competing interests: None declared.

Ethics approval: Oxford Psychiatric Research ethics committee and the London School of Hygiene and Tropical Medicine ethics committee.

1 Hawton K, Arensman E, Townsend E, Bremner S, Feldman E, Goldney R, et al. Deliberate self-harm: systematic review of efficacy of psychosocial and pharmacological treatments in preventing repetition. BMJ 1998;317:441-7.

2 National Institute for Clinical Excellence. The short-term physical and psychological management and secondary prevention of self-harm in primary and secondary care. London: NICE, 2004.

3 Bennett S, Coggan C, Adams P. Problematising depression: young people, mental health and suicidal behaviours. Soc Sci Med 2003;57:289-99.
4 Coggan C, Patterson P, Fill J. Suicide: qualitative data from focus group interviews with youth. Soc Sci Med 1997:45:1563-70

5 Redley M. Towards a new perspective on deliberate self-harm in an area of multiple deprivation. Sociol Health Illn 2003;25:348-73.

6 Everall RD. The meaning of suicide attempts by young adults. Can J Couns 2000;34:111-25.

7 Tyrer P, Thompson S, Schmidt U, Jones V, Knapp M, Davidson K, et al. Randomized controlled trial of brief cognitive behaviour therapy versus treatment as usual in recurrent deliberate-harm: the POPMACT study. Psychol Med 2003;33:969-76.

8 Frank AW. The wounded story teller: body, illness and ethics. Chicago: University of Chicago Press, 1997.

9 Charmaz K. Stories of suffering: subjective tales and research narratives. Qual Health Res 1999:9:362-82.

10 Haw C, Hawton K, Houston K, Townsend E. Psychiatric and personality disorders in deliberate self-harm patients. Br J Psychiatry 2001;178:48-54.

11 Hawton K, Houston K, Haw C, Townsend E, Harriss L. Comorbidity of axis I and axis II disorders in patients who attempt suicide. Am J Psychiatry 2003;160:1494-500.

12 Platt S, Bille-Brahe U, Kerkhof A, Schmidtke A, Bjerke T, Crepet P, et al. Parasuicide in Europe: the $\mathrm{WHO} / \mathrm{EU}$ multicentre study on parasuicide. I. Introduction and preliminary analysis for 1989. Acta Psychiatr Scand 1992;85:97-104.

13 Hammersley M. The generalisability of ethnography. In: Hammersley M, ed. What's wrong with ethnography? London: Routledge, 1992:85-95.

14 Strauss A. Qualitative analysis for social scientists. Cambridge: Cambridge University Press, 1987.

15 Green J. Commentary: grounded theory and the constant comparative method. BMJ 1998;316:1064-5.

16 Green J, Thorogood N. Qualitative methods for health research. London: Sage, 2004.

17 Beck AT, Schuyler D, Herman I. Development of suicidal intent scales. In: Beck AT, Resnick H, Lettieri DJ, eds. The prediction of suicide. Philadelphia, PA: Charles Press, 1974:45-56.

18 Hawton K, Hall S, Simkin S, Bale E, Bond A, Codd S, et al. Deliberate self-harm in adolescents: a study of characteristics and trends in Oxford, 1990-2000. J Child Psychol Psychiatry 2003;44:1191-8.

19 Hawton K, Rodham K, Evans E, Weatherall R. Deliberate self-harm in adolescents: self report survey in schools in England. BMJ 2002;325:1207-11.

20 Harris EC, Barraclough B. Suicide as an outcome for mental disorders. A meta-analysis. BrJ Psychiatry 1997;170:205-28.

21 Pirkola SP, Suominen K, Isometsa ET. Suicide in alcohol-dependent individuals: epidemiology and management. CNS Drugs 2004;18:423-36.

22 Crawford MJ, Patton R, Touquet R, Drummond C, Byford S, Barrett B, et al. Screening and referral for brief intervention of alcohol-misusing patients in an emergency department: a pragmatic randomised controlled trial. Lancet 2004;364:1334-9. (Accepted 22 March 2005)

doi $10.1136 /$ bmj.38441.503333.8F

Centre for Suicide Research, University Department of Psychiatry, Warneford Hospital, Oxford OX3 7JX

Julia Sinclair MRC special training fellow in health service research

Health Services Research Unit, London School of Hygiene and Tropical Medicine, London WC1E 7HT

Judith Green senior lecturer

Correspondence to:J Sinclair julia.sinclair@psych.ox.ac.uk 